\title{
Contrast sensitivity function of preschool children
}

\author{
JANETTE ATKINSON, JENNIFER FRENCH, AND OLIVER BRADDICK \\ From the Kenneth Craik Laboratory, University of Cambridge
}

SUMMARY A procedure specifically adapted for children of preschool age has been used to measure contrast sensitivity in emmetropic children aged 3 to 5 years. Mothers of the children acted as adult observers using the same procedure. The results show that the contrast sensitivity function of adults and children is very similar, sensitivity for the children being slightly lower than that for adults at all spatial frequencies. The sensory and cognitive factors involved in these differences are discussed.

Conventional measurements of visual acuity, such as the Snellen letter chart, yield estimates of the finest resolvable detail at maximum contrast (usually black letters on a white background). The contrast sensitivity function gives a much broader measure of visual function, because it gives a measure of visual sensitivity for low-contrast patterns of any degree of 'fuzziness' as well as for fine detail. Acuity corresponds to one point, the high spatial frequency limit, of the contrast sensitivity function.

In recent years it has been found that measurements of contrast sensitivity can yield relevant diagnostic information for a number of clinical disorders. $^{1-4}$ Although we know the form of the contrast sensitivity function for normal adults ${ }^{5}$ and for young infants, ${ }^{6-10}$ we have little idea about it in normal preschool children. From earlier studies of acuity in children it has been found that the nature of the test material and the exact procedure have a marked effect on acuity estimates in this age group. 11-17 Similarly the one published study of contrast sensitivity ${ }^{18}$ clearly shows that standard adult means of measurement give very limited results from preschool children. In fact in this study only 6 out of 243 -year-old children completed the tests, suggesting that it was not a suitable method for the majority of children of this age. Here we report results of contrast sensitivity measurements on preschool children where the test has been specifically adapted for this age group.

From previous studies it has been found that there is a very rapid development of contrast sensitivity,

Correspondence to Department of Experimental Psychology, University of Cambridge, Downing Street, Cambridge CB2 3EB. including acuity, in the first 6 months of life. Presumably the subsequent development to adult levels is more gradual. From measurements that have been reported on children of school age it seems that there is still a difference in contrast sensitivity between these children and adults. ${ }^{18}$ Here we investigate how close the vision of the preschool child is to that of the adult using the same test for both. A preliminary account of our overall results has already been presented. ${ }^{19} \mathrm{We}$ now describe the procedure and give a fuller analysis of the findings.

\section{Materials and methods}

STIMULI

The stimuli were black-and-white grating patterns mounted on the inner surfaces of transparent acrylic cubes $(7.6 \mathrm{~cm}$ high by $8.9 \mathrm{~cm}$ wide) of the type commercially available for displaying photographs. For measurements of contrast sensitivity the gratings were black-and-white photographic prints of sinusoidal grating patterns taken from an oscilloscope screen, with care being taken in exposure and processing to obtain prints whose density was a linear function of the original light intensity. A set of prints was used whose contrast ranged from $0.75 \%$ to $47 \%$. Spatial frequencies of $0.3,1 \cdot 5$, and 3 cycles/deg were obtained by presenting the same cubes at $30 \mathrm{~cm}, 1.5 \mathrm{~m}$, and $3 \mathrm{~m}$. The acuity point on the contrast sensitivity function was determined, by using high-contrast square-wave gratings made from Letraset sheet no. LT 213, and varying the viewing distance between $1 \mathrm{~m}$ (giving a spatial frequency of 20 cycles/deg) and $3 \mathrm{~m}$ ( 60 cycles/ deg) in $50 \mathrm{~cm}$ steps. Each cube had identical patterns 
mounted on 4 sides, with the side facing the child changed on each trial to minimise any chance of a child responding to any irrelevant mark on the surface. For each pattern 2 cubes were prepared, one with the grating stripes vertical and one horizontal. Each cube was packed with polyurethane foam, with a small piece cut out of the base of the foam so that a reward could be concealed under the cube. Sweets, crisps, beads, adhesive gold stars, or marbles were used as rewards.

Two cubes were presented on each trial, as shown in Fig. 1. A barrier down the centre of the room directly beneath the room light made it possible to fix the closest point at which the child had to decide between the cubes. The extent of the barrier could be altered to manipulate the distance for viewing between 1 and $3 \mathrm{~m}$. For testing at $30 \mathrm{~cm}$ each child sat at a high table so that the cubes were at eye level. The distance from the cubes was set by a fixed face mask through which the children viewed a pair of cubes. Instead of running to one or other side of the barrier, to the chosen cube, they were asked to indicate their choice by pointing with either their left or right hand to the cube on that side. The tester then lifted the cube to which they had pointed so that the child saw whether the choice was correct.

\section{SUBJECTS}

The children were part of our volunteer sample coming from the Cambridge area. The results reported are for 20 children between the ages of 3 and 5 years who completed testing. Three other children did not complete all the testing because of waning co-operation. Some of the children were tested in pairs, with one child completing a trial followed by the other and so on. To obtain 4 points on the contrast sensitivity function required extensive testing of each child, usually spread over 3 or 4 different testing periods. There were at least 40 trials for each threshold measurement, giving at least 160 trials in all for each child. Six of the mothers of the children acted as adult observers. All the children and adults were able to accommodate at the target distance, without astigmatism, as measured by photorefraction. ${ }^{20}$

\section{PROCEDURE}

On each trial a vertical grating was presented on one side and a horizontal grating on the other. The task was explained to the child as follows: 'I'm going to put a present underneath the striped box which has the "standing up" (or "lying down") stripes on it' (the meaning of these phrases was demonstrated by showing the appropriate cube) 'and I want you to run to the right cube to get the present. If it's difficult for you to see the stripes just make a guess and we'll see whether you got it right or not.'

Each child was first of all tested to see if they understood the task, by using the cubes with the $47 \%$ contrast sinusoidal grating at 3 metres. Three

Fig. 1 Diagram of the set-up for testing preschool children. The cubes were randomly placed to either the left or the right side of the barrier. The length of the barrier could be adjusted for different viewing distances.

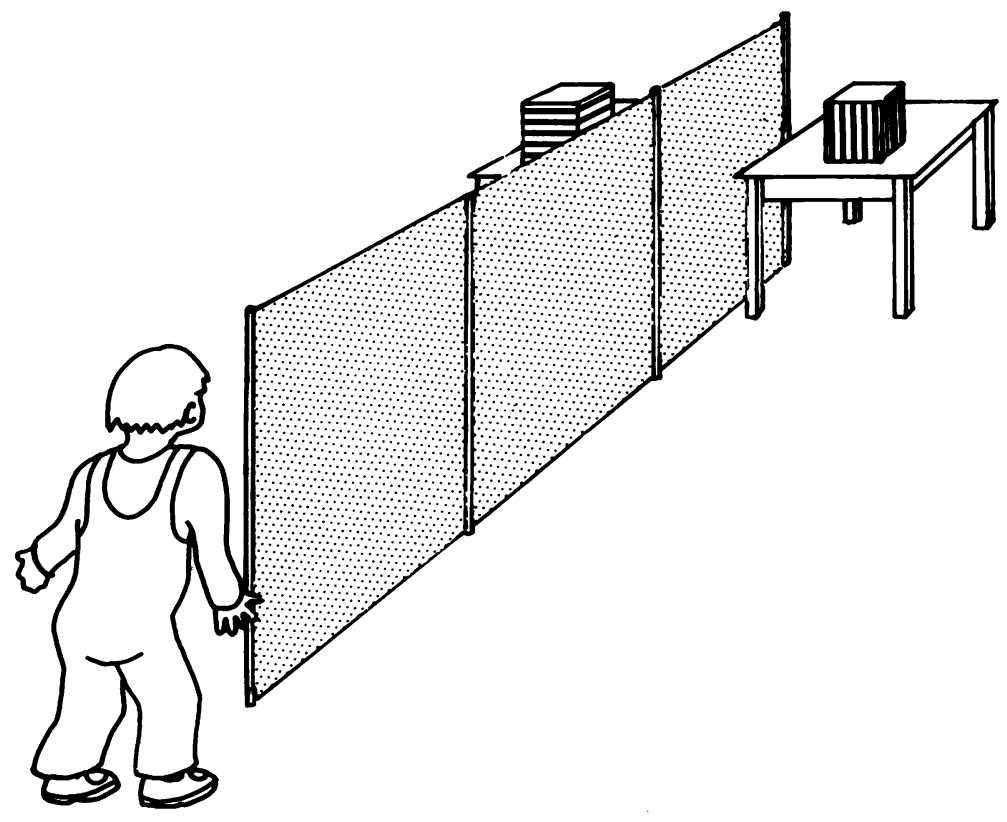


trials were given with an appropriate reward under either the vertical or horizontal stripes and the side of the positive stimulus varied in a random sequence from trial to trial. If all 3 of these pilot trials were correct and the child seemed to be performing with ease and confidence, a cube with a much lower contrast, just above adult threshold, was used. Half of the children were rewarded for the horizontal stripes and half for the vertical on all testing sessions, with each child randomly allocated to one or other group. The order of testing at different distances (and thereby different spatial frequencies) was randomised across subjects. For many of the children there was an initial hesitation to make a choice when the contrast was near threshold, so throughout testing we inserted 'dummy' trials to maintain attention and performance, using the high contrast stimuli on which the child had performed correctly at the beginning of testing. To keep motivation high we also allowed the child from time to time to retrace his steps after he had made an incorrect choice, and go to obtain a reward at the other cube. The first (incorrect) choice was recorded by the tester on these trials. Between trials the child's face was turned away from the cubes and his eyes were covered by a tester's hands while the cubes were set up.

When the mothers were tested they were simply asked to tell the tester which cube had vertical or horizontal stripes on it, again the side of positive stimulus being kept constant.

The stimulus used on each trial was determined by a staircase procedure. Five trials were given at each contrast level (or distance in the case of acuity measurements) before moving to a new contrast or distance. The staircase was continued until at least 20 trials were obtained on each of 2 or more contrast values (or spatial frequencies if testing acuity), with performance above $70 \%$ correct on one stimulus and below on another. The $70 \%$ correct point was interpolated from these results and taken as the estimate of threshold.

\section{Results}

The children's results were divided for the purpose of analysis into 3 age groups: $3-3 \frac{1}{2}$ years $(n=6$, mean age 3 years 2 months), $3 \frac{1}{2}-4$ years $(n=8$, mean age 3 years 10 months), and $4-4 \frac{3}{4}$ years ( $n=6$, mean age 4 years 7 months). The means and standard deviations of the threshold estimates are shown in Fig. 2 for the 3 age groups of children and the adult controls. There is clearly much overlap between the groups, but the means show a steady improvement in visual performance with age, the adults having higher mean values than the children at all spatial frequencies. Trend analysis ${ }^{21}$ was carried out on the results of the 3 groups of children but showed no significant age trend at the $p<0.05$ level.

Detection of a grating with a spatial frequency of $30 \mathrm{c} / \mathrm{deg}$ is generally taken as equivalent to $6 / 6$ vision for a Snellen letter chart. It can be seen from the present results that all the adults detected gratings

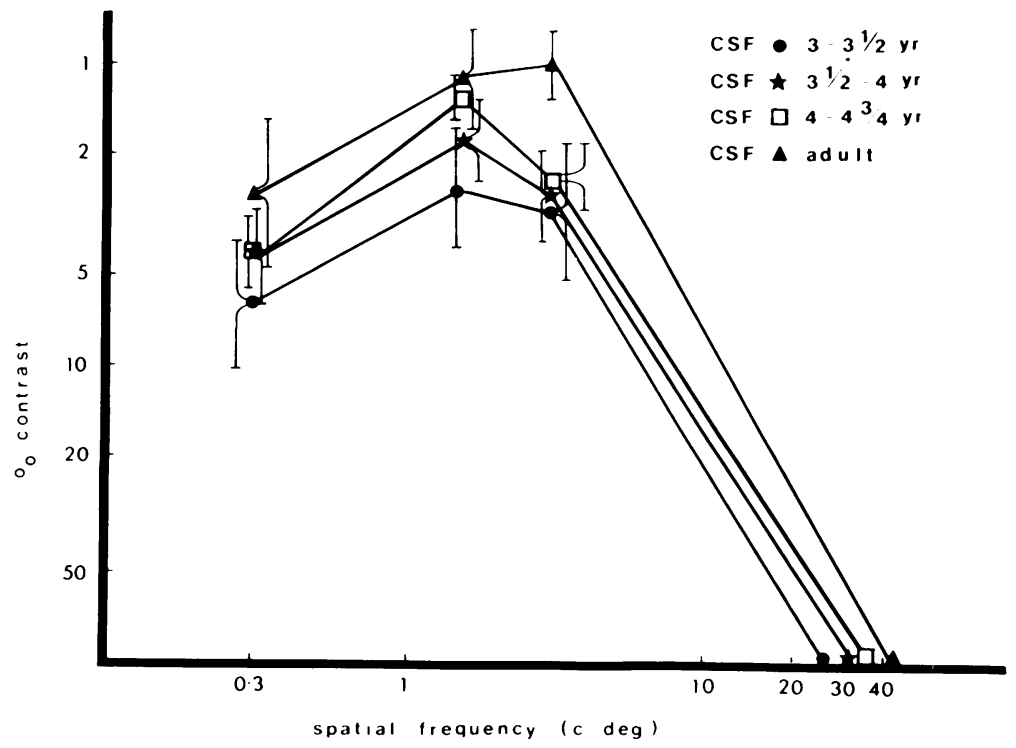

Fig. 2 The mean contrast sensitivity function for different age groups of preschool children and for adults. The bars above and below each point represent the standard deviation of individual subjects. Standard deviations of the acuity values have been omitted for reasons of space. The ranges for $\pm 1 S D$

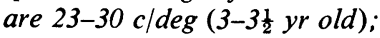

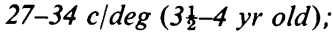

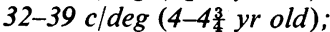
41-50 c/deg (adults). 
finer than $30 \mathrm{c} / \mathrm{deg}$, as did 17 out of the 20 children, and so these individuals would be expected to have at least $6 / 6$ vision if tested conventionally.

\section{Discussion}

There have been several studies measuring acuity in preschool children, with the results varying with the test material, procedure, criterion for successful performance, and sample. Slataper ${ }^{12}$ and Allen ${ }^{15}$ reported average 3-year-old acuity to be 6/12. Woodruff ${ }^{13}$ found an acuity of $6 / 6$ in $70 \%$ of his preschool group as did Smørvik and Bosnes ${ }^{14}$ for their sample of 2-6-year-olds. Our present results show that all but 3 of the children in our group showed acuities equivalent to $6 / 6$ vision (i.e., over $30 \mathrm{c} / \mathrm{deg}$ ), but the average acuity of the adults was higher than that of the children.

There is only one previously reported study of contrast sensitivity in a small group of preschool children ${ }^{18}$ for comparison with the present results. Much better visual performance was shown in the present study, with both higher contrast thresholds and acuity values.

The most meaningful comparison is between the adults' and children's results in the present study, which used the same test materials and analogous procedures. Contrast sensitivity, like acuity, appears somewhat lower for the preschool children. The reason for this difference is uncertain. It may reflect a genuine development of sensory capacity. If so, we do not know the basis of this difference; those anatomical and physiological indices which have been studied ${ }^{22-24}$ show adult levels being attained around 2 years or earlier.

Performance on vision tests may also depend on the development of the child's understanding of what the test requires. Radical cognitive changes occur in children during the preschool and early school years. ${ }^{25} 26$ More subtly, children's selfawareness of their intellectual and physical limitations (sometimes called 'metacognition' ${ }^{27}$ ) develops over the same period. This may be important for high performance on visual discriminations near threshold. In such tasks observers have to be prepared to 'guess' in cases of uncertainty: adult observers are often surprised to find that their choices are often reliably correct even when they are felt to be almost pure guesses. Our observations of young children's behaviour in this experiment suggest that the requirement to recognise their own state of sensory uncertainty and to make the best guess is too sophisticated for them. Children who perform confidently on easy discriminations often appear to abandon any attempt to make a visual discrimination when the task becomes difficult and instead adopt some 'strategy' or rule of behaviour unrelated to the patterns, such as always running to the same side or regularly alternating between sides.

The difference between the adults' and children's performance was most marked at the lowest spatial frequency. We do not know the reason for this result. It may be due to the different procedure we adopted at the low spatial frequency. The children had to look through a face mask, which was a somewhat unwelcome constraint for them, and did not give them the opportunity to confirm their judgments by running to the cube and inspecting it (the low frequency grating is actually harder to detect on closer inspection). We suspect that the children may have given up the attempt to discriminate, and lapsed into nonvisual strategies, at an earlier stage in this task than in the more motivating running task.

\section{CONCLUSION}

We find that the 'alley running' task is a practical means of testing vision in 3-5-year-olds and gives results on contrast sensitivity that are much closer to adult values than those from methods that are less specifically adopted to young children. Most 3-4-year-olds attain $30 \mathrm{c} / \mathrm{deg}$ acuity, conventionally equivalent to $6 / 6$. The differences found between children and adults may be due to cognitive development as well as sensory development. For most practical purposes the 3-5-year-old can be considered to have normal adult acuity and contrast sensitivity.

We thank Mr Peter Starling from the Physiological Laboratory, University of Cambridge, for providing us with the photographic prints. This research was supported by the Medical Research Council of Great Britain.

\section{References}

1 Bodis-Wollner I, Diamond SP. The measurement of spatial contrast sensitivity in cases of blurred vision associated with cerebral lesions. Brain 1976; 99: 695-710.

2 Regan D, Silver R, Murray TJ. Visual acuity and contrast sensitivity in multiple sclerosis, hidden visual loss: an auxiliary test. Brain 1977; 100: 563-79.

3 Arden GB, Jacobsen JJ. A simple grating test for contrast sensitivity: preliminary results indicate value for screening in glaucoma. Invest Ophthalmol Visual Sci 1978; 100: 23-52.

4 Hess RF, Howell ER. The threshold contrast sensitivity function in strabismic amblyopia: evidence for a two type classification. Vision Res $1977 ; 17$ : 1049-55.

5 Campbell FW, Robson JG. Application of Fourier analysis to the visibility of gratings. $J$ Physiol 1968; 197: 551-66.

6 Atkinson J, Braddick O, Moar K. Development of contrast sensitivity over the first three months of life in the human infant. Vision Res 1977 ; 17 : 1037-44.

7 Atkinson J, Braddick O, Moar K. Contrast sensitivity 
of the human infant for moving and static patterns. Vision Res 1977 ; 17 : 1045--7.

8 Banks MS, Salapatek P. Acuity and contrast sensitivity in 1-, 2-, and 3-month-old human infants. Invest Ophthalmol Visual Sci 1978; 17: 361-5.

9 Harris L, Atkinson J, Braddick O. Visual contrast sensitivity of a 6 -month-old infant measured by the evoked potential. Nature 1976; 264: 570-1.

10 Pirchio M, Spinelli D, Fiorentini A, Maffei L. Infant contrast sensitivity evaluated by evoked potentials. Brain Res 1978; 141: 179-84.

11 Brant JC, Nowotny M. Testing visual acuity in young children: an evaluation of some commonly used methods. Dev Med Child Neurol 1976; 18: 568-76.

12 Slataper FJ. Age norms of refraction and vision. Arch Ophthalmol 1950; 43: 466-81.

13 Woodruff ME. Observations on the visual acuity of children during the first five years of life. Am J Optom 1972; 49: 205-15.

14 Smørvik D, Bosnes O. Assessment of visual acuity in preschool children. Scand J Psychol 1976; 17: 122-4.

15 Allen HF. Testing of visual acuity in preschool children. Pediatrics 1957; 19: 1093-100.

16 Lippmann $\mathrm{O}$. Vision screening of young children. $A m \mathrm{~J}$ Public Health 1971; 61: 1586-601.

17 Hilton AF, Stanley JC. Pitfalls in testing children's vision by the Sheridan Gardiner single optotype method. Br J Ophthalmol 1971; 56: 135-9.
18 Beazley LD, Illingworth DJ, Jahn A, Greer DV. Contrast sensitivity in children and adults. $\mathrm{Br} \mathrm{J}$ Ophthalmol 1980; 64: 863-6.

19 Atkinson J, Braddick O. New techniques for assessing vision in infants and young children. Child Care Health Dev 1979; 5: 389-98.

20 Braddick OJ, Atkinson J, French J, Howland HC. A photorefractive study of infant accommodation. Vision Res 1979 ; 19: 1319-30.

21 Jonckheere AR. A distribution-free $k$-sample test against ordered alternatives. Biometrika 1954; 41: 133-5.

22 Friede RL, Hu KH. Proximo-distal differences in myelin development in human optic fibres. Z Zellforsch 1967; 79: 259-64.

23 Hickey TL. Postnatal development of the human lateral geniculate nucleus: relationship to a critical period for the visual system. Science $1977 ; 198$ : 836-8.

24 Hrbek A, Vitova S, Mares P. The development of cortical evoked responses to visual stimulation during childhood. Act Nerv Super 1966; 8: 39-46.

25 Piaget J. The The Language and Thought of the Child. London: Routledge and Kegan Paul, 1956.

26 Gelman R. Preschool thought. Am Psychol 1979; 34: 900-5.

27 Flavell JH. Metacognition and cognitive monitoring: a new area of cognitive-developmental inquiry. $\mathrm{Am}$ Psychol 1979; 34: 906-11. 